\title{
Plasma Somatostatin and Cholecystokinin Levels in Preterm Infants and Their Mothers at Birth
}

\author{
C.-J. TÖRNHAGE, F. SERENIUS, K. UVNÄS-MOBERG, AND T. LINDBERG \\ Department of Pediatrics, Umeå University, Umeå [C.-J.T., F.S., T.L.] and Department of Pharmacology, \\ Karolinska Institute, Stockholm, Sweden [K.U-M.]
}

\begin{abstract}
Regulatory gut peptides play an important role in regulating
ABST
the gastrointestinal tract. Our knowledge about the pattern of
secretion and function of these peptides is scanty in preterm
infants. Therefore, plasma somatostatin (SS) and cholecystokinin
(CCK) levels were estimated just after birth in 65 mothers and 73
preterm infants (umbilical cord blood). The gestational age was
$32(24-36$ median ranges) wk and birth weight $1900(475-3350)$
g. The umbilical cord blood pH was $7.32 \pm 0.10$ (mean $\pm \mathrm{SD}$ ).
After Sep-Pak- $\mathrm{C}_{18}$ semichromatography of plasma, SS and CCK
were analyzed by RIA. Both plasma SS and CCK levels were
significantly higher in infants than in mothers (SS $=14.5 \pm 12.4$
versus $9.3 \pm 7.6$ pmol/L; CCK $=11.6 \pm 7.4$ versus $7.0 \pm 1.9$
pmol/L). In appropriate for gestational age and small for gesta-
tional age infants' plasma levels of the two peptides were the
\end{abstract}
More than 100 polypeptides called "regulatory gut peptides" are produced in endocrine cells which are located in the gastrointestinal mucosa (1). The release of these peptides into the gut lumen and into the blood is stimulated by certain substances present in the gastrointestinal lumen. The release of peptides from the proximal part of the gastrointestinal tract is also under nervous control. Our knowledge of the function of these regulatory gut peptides in early life is incomplete. It has been shown that the plasma levels of some peptides, e.g. SS, $\mathrm{CCK}$, and gastrin, are altered in various ways in different situations in term infants (2-4). SS and CCK are of special interest because of their opposite function and differing nervous regulation in stressful situations.

$\mathrm{CCK}$ is produced in $\mathrm{I}$-cells in the proximal third of the intestine. It stimulates gastrointestinal peristalsis, inhibits secretion of gastric acid, contracts the gallbladder, relaxes the sphincter of Oddi, and hence stimulates secretion of bile and of enzyme-rich pancreatic juice. It has a trophic effect on the exocrine pancreatic gland and a tendency to induce satiety and

Received June 15, 1994; accepted December 20, 1994.

Correspondence: Dr. Carl-Johan Törnhage, Department of Pediatrics, Umeå University, S-901 85 Umeå, Sweden.

Supported by grants from the Foundation of Ring, Lundgren in Umeå, the Foundation of First of May Flower Annual Campaign and the Foundation of Preterm Research in Lund, Swedish Medical Research Council, Project No 14X-05207. same. They were also independent of sex, birth weight, gestational age, umbilical cord blood $\mathrm{pH}$, or glucose level. In mothers, but not in infants, plasma SS levels were higher after vaginal delivery than after cesarean section. After multiple birth, newborn plasma SS, but not plasma CCK, was significantly lower than after single birth $(9.1 \pm 7.7$ versus $16.9 \pm 12.7 \mathrm{pmol} / \mathrm{L})$. (Pediatr Res 37: 771-776, 1995)
SS, somatostatin
Abbreviations
CCK, cholecystokinin
GA, gestational age
AGA, appropriate for gestational age
SGA, small for gestational age

suppress food intake. The parasympathetic nervous system stimulates the secretion of CCK $(5,6)$.

$\mathrm{SS}$ is produced in the D-cells of the gastric mucosa. It inhibits gastrointestinal peristalsis, gastrin release, and the secretion of gastric acid. It also inhibits the secretion of CCK, vasoactive intestinal peptide, secretin, growth hormone, and prolactin, and by inhibiting insulin release, increases the blood glucose. SS inhibits pancreatic and gastrointestinal mucosal growth. The sympathetic nervous system stimulates the SS release $(5,6)$.

It is not known how the degree of immaturity, mode of delivery, sex, type of feeding, or various disorders and treatments influence the plasma levels of these peptides in immature infants. In this study we measured the plasma levels of SS and CCK in the mother and the immature infant at the time of birth. Results on the infants were assessed relative to sex, GA, birth weight, femoral length, placenta weight, single and multiple birth, mode of delivery, Apgar score, and pH and blood glucose of the umbilical blood.

\section{METHODS}

Patients. From April 1991 to March 199368 mothers, who delivered before term, agreed to participate in the study. Their age ranged from 18 to $42 \mathrm{y}$ with a mean of $28 \mathrm{y}$. Thirty-one mothers were delivered vaginally and 37 by cesarean section, 
of which 12 were acute and 25 were electively planned. Venous blood samples were obtained from 65 of these mothers.

The mothers gave birth to 81 infants; umbilical cord blood was obtained from 73 infants included in the study. Data from these infants are shown in Table 1. Thirty-seven of the infants were boys; 11 were SGA, 58 were AGA; and four were large for GA. Of the 73 infants, 57 were singleton births, and the remainder were twins or infants of higher birth order.

There was insufficient blood to analyze SS and CCK in all mothers and infants. The $n$ values of plasma SS and plasma $\mathrm{CCK}$ therefore differ in tables and figures.

Chemicals. Methanol and acetic acid were purchased from Merck (Darmstadt, Germany), acetonitrile from Baker (Deventer, Holland), aprotinin (Trasylol) and chlorbutanol from Bayer AG (Leverkusen, Germany), and heparin from Kabi Pharmacia AB (Uppsala, Sweden).

CCK-sulfated octapeptide (CCK 26-33) and SS (lot no. 8001) from Peninsula Lab. Europe Ltd (St. Helens Merseyside, UK) were used as standards. ${ }^{125} \mathrm{I}-\mathrm{CCK}$ and ${ }^{125} \mathrm{I}$-SS from DuPont NEN Research Products (Boston, MA) were used as tracers. As antibodies we used the specific CCK antibody OAL-656 (Otsaka Assay Laboratories, Tukoshima, Japan) (7) and SS antibody R141E, which was a generous gift of Dr. Efendic. The CCK antibody OAL-656 recognizes sulfated CCK-8, CCK-33, and CCK-39, whereas sulfated gastrin-17, unsulfated gastrin-17, and gastrin-34 is recognized to less than $0.1 \%$.

SS antibody R141E recognizes both SS 14 and 28. Crossreactivity of the antibodies was less than $0.01 \%$ with insulin, glucagon, substance P, LH-releasing hormone, vasopressin, and oxytocin (8).

The study was approved by the ethical committee of the Medical faculty, Umeå University. The mothers/parents received oral and written information and gave her/their consent to the investigation.

Procedure. The estimation of GA was based on ultrasound at $16-18 \mathrm{wk}$ in 52 mothers. In 16 mothers the GA estimation was based on the mothers' recollection of the first day of the last normal menstrual period. Infants with a GA of more than 28 wk were classified as AGA, SGA, and large for GA according to Swedish birth weight curves (9), whereas infants less than 28 wk of GA were similarly classified according to the birth weight curves of Lubchenco et al. (10). For attained femoral length the standard of Persson and Weldner (11) was used.

Table 1. Data on infants at birth

\begin{tabular}{lcccl}
\hline \multicolumn{1}{c}{ Characteristic } & $n$ & Range & mean \pm SD & \multicolumn{1}{c}{ Comment } \\
\hline Gestational age, wk & 73 & $24-36$ & 32 & $9<28$ \\
Birth weight, g & 73 & $475-3350$ & 1900 & $11<1000$ \\
Birth length, cm & 73 & $28.0-52.0$ & 43.0 & $8<35.0$ \\
Apgar score 5 min & 73 & $5-10$ & 9 & $4<7$ \\
Umbilical blood pH & 57 & & $7.32 \pm 0.10$ & $11<7.25$ \\
Umbilical blood glucose, & 45 & & $3.8 \pm 1.4$ & $3<2.0$ \\
$\quad$ mmol/L & & & & \\
Placenta weight, $\mathrm{g}^{a}$ & 44 & & $440 \pm 141$ & Minimum 150 \\
\hline
\end{tabular}

${ }^{a}$ Single births only.
As soon as possible after delivery venous blood samples were taken from the mothers (1-270 min, median $25 \mathrm{~min}$ ) and from the umbilical cords (1-180 min, median $8 \mathrm{~min}$ ) into icechilled tubes. Each tube, containing heparin $(10 \mathrm{IU} / \mathrm{mL}$ blood), chlorbutanol (10 $\mu \mathrm{g} / \mathrm{mL}$ blood), and aprotinin (Trasylol, 500 $\mathrm{kIU} / \mathrm{mL}$ blood) was filled with $3 \mathrm{~mL}$ blood. (To avoid contamination of the heparin/Trasylol solution with bacteria (Pseudomonas aeruginosa) we added chlorbutanol. Ten control blood samples with and without chlorbutanol gave the same RIA results.) Within 45 min they were centrifuged (room temperature, at 2000 rpm) for $10 \mathrm{~min}$, and plasma was stored frozen at $-20^{\circ} \mathrm{C}$ until analyzed.

After thawing, the plasma samples were centrifuged $\left(+4^{\circ} \mathrm{C}\right.$ at $2000 \mathrm{rpm}$ for $10 \mathrm{~min}$ ), and $0.2 \mathrm{~mL}$ plasma was purified with reversed-phase chromatography with Sep-Pak $\mathrm{C}_{18}$ cartridges, Waters Millipore Corporation, Marlboro, MA (12) for each analyzis.

Briefly the SS assay was conducted as follows: $0.2 \mathrm{~mL}$ plasma was acidified with an equal volume of $0.25 \mathrm{M} \mathrm{HCl}$. Each Sep-Pak $\mathrm{C}_{18}$ cartridge was activated with $5 \mathrm{~mL}$ methanol and $20 \mathrm{~mL}$ water before the acidified plasma was applied to the cartridge. After washing with $20 \mathrm{~mL} 4 \%$ acetic acid, the sample was eluted with $2 \mathrm{~mL}$ of methanol. The eluted sample was dried in a vacuum centrifuge and later redissolved in 250 $\mu \mathrm{L}$ of the SS assay buffer. The aliquots of $100 \mu \mathrm{L}$ were assayed in duplicate by RIA (13). The limit of detection for the $\mathrm{SS}$ assay was $2 \mathrm{pmol} / \mathrm{L}$. The intrassay and interassay coefficients of variations were 11 and $9 \%$, respectively.

The CCK assay was conducted as follows. Each Sep-Pak $\mathrm{C}_{18}$ cartridge was activated with $10 \mathrm{~mL}$ of $100 \%$ acetonitrile and then washed with $10 \mathrm{~mL}$ of $0.1 \%$ acetic acid. The plasma sample was applied to the Sep-Pak $\mathrm{C}_{18}$ cartridge in $0.2-\mathrm{mL}$ portions. After washing with $5 \mathrm{~mL}$ of $0.1 \%$ acetic acid, the sample was eluted with $5 \mathrm{~mL} 0.1 \%$ acetic acid and $100 \%$ acetonitrile (50-50 vol \%). The eluted sample was dried in a vacuum centrifuge and later redissolved in $250 \mu \mathrm{L}$ of the CCK assay buffer. Aliquots of $100 \mu \mathrm{L}$ were assayed in duplicate by RIA (14). The limit of detection of the CCK assay was 2.5 $\mathrm{pmol} / \mathrm{L}$. The intra- and interassay coefficients of variations were 5 and $15 \%$, respectively.

Statistics. All calculations were performed at the Institute of Mathematical Statistics, Umeå University. The SYSTAT computer program (15) was used to carry out Pearson's matrix for correlation, Bonferroni's adjustment for probability, Wilcoxon's signed ranks test, and the Mann-Whitney $U$ test. $p$ values less than 0.05 were considered statistically significant.

\section{RESULTS}

Figure 1, $a$ and $b$, shows individual infant plasma SS and CCK values immediately after birth in relation to GA and to the femoral length standard. SS and CCK could be detected even in the most immature infants. There was no correlation between SS or CCK values and GA or the slope of the femoral length standard, as shown in the figures. Additionally there was no correlation between SS or CCK values and birth weight, birth length, or placental weight (data not shown). 


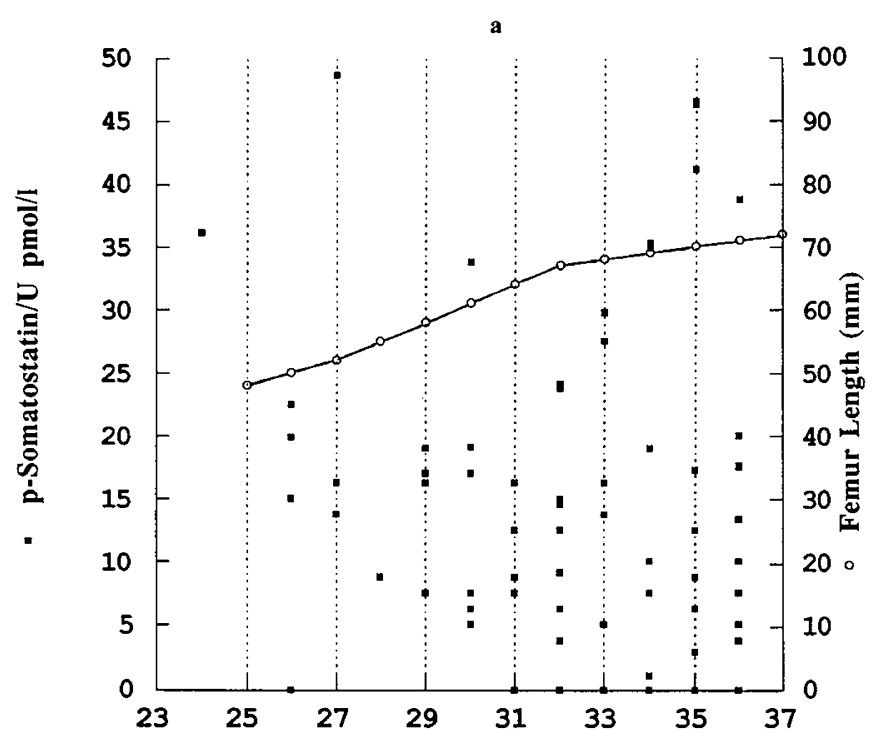

Gestational Age (weeks)

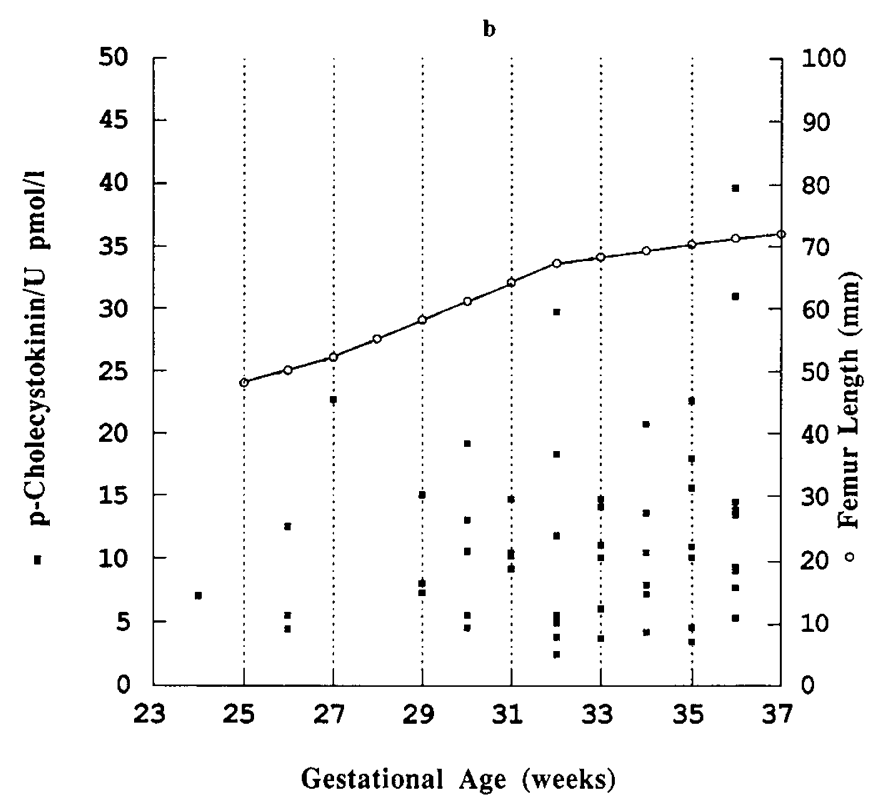

Figure 1. Umbilical cord plasma SS $(a)$ and CCK $(b)$ levels in relation to GA and femur length $(O)$.

Figure 2, $a$ and $b$, shows individual maternal plasma SS and CCK values in relation to GA. There was no correlation between plasma SS and CCK values on the one hand and GA, birth weight, birth length, or placental weight on the other.

Table 2 shows the mean plasma levels of SS and CCK in mothers and infants at birth. The mean infant plasma SS level was significantly higher than that of the mother. When the material was stratified according to GA, the mean infant plasma SS levels tended to be higher than those of the mothers for all GA groups, but the mean level was significantly higher only to infants $>31 \mathrm{wk}$ of GA. There was a similar trend to higher CCK levels in infants than in mothers and again the higher value was significant only for infants $>31$ wk of GA. There was no correlation, however, between individual maternal and infant levels of plasma CCK. There was a significant
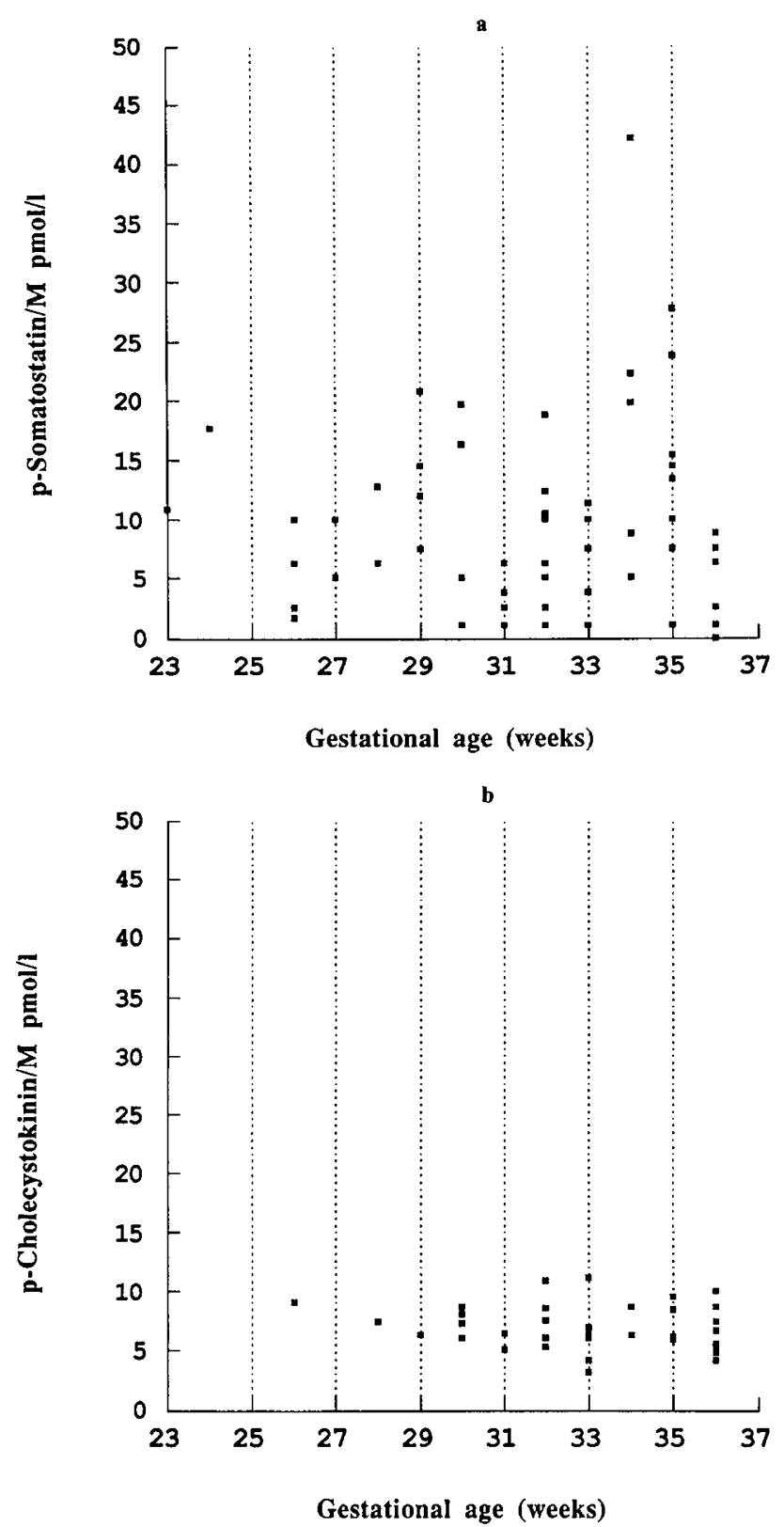

Figure 2. Maternal plasma SS $(a)$ and CCK $(b)$ levels after birth in relation to GA.

positive correlation between the individual plasma SS values in the mother and those of the infant, as shown in Figure 3. Maternal levels of SS and CCK were not correlated nor were the infant levels.

Table 3 compares mean maternal and infant SS and CCK levels according to the mode of delivery. The mean plasma SS level was significantly higher in mothers who delivered vaginally compared with those who delivered by cesarean section. Plasma SS levels in mothers who underwent acute cesarean section were similar to those who were electively sectioned. Mean maternal levels of CCK and mean levels of SS or CCK in infants were similar after vaginal and cesarean section delivery.

There was no correlation between plasma SS and CCK values on one hand and Apgar score at $5 \mathrm{~min}$, umbilical cord blood $\mathrm{pH}$, or blood glucose on the other. 
Table 2. Plasma SS and CCK levels in mothers and infants after preterm birth according to the length of gestation

\begin{tabular}{crrrlc}
\hline Plasma & $n$ & Mother & $n$ & Infant & $p$ \\
\hline SS, pmol/L & & & & & \\
$<28 \mathrm{wk}$ & 8 & $8.0 \pm 5.2$ & 8 & $21.5 \pm 14.8$ & $*$ \\
$28-31 \mathrm{wk}$ & 12 & $10.6 \pm 6.3$ & 14 & $12.9 \pm 9.6$ & $*$ \\
$>31 \mathrm{wk}$ & 43 & $9.2 \pm 8.3$ & 50 & $13.8 \pm 12.5$ & 0.003 \\
All infants & 63 & $9.3 \pm 7.6$ & 72 & $14.5 \pm 12.4$ & 0.001 \\
CCK, pmol/L & & & & & \\
$<28$ wk & 2 & $9.1 \pm 0.01$ & 5 & $10.4 \pm 7.5$ & $*$ \\
$28-31 \mathrm{wk}$ & 8 & $7.2 \pm 1.3$ & 11 & $10.6 \pm 4.8$ & $*$ \\
$>31$ wk & 28 & $6.8 \pm 2.0$ & 38 & $12.1 \pm 8.1$ & 0.008 \\
All infants & 38 & $7.0 \pm 1.9$ & 54 & $11.6 \pm 7.4$ & 0.004 \\
\hline
\end{tabular}

Values are means \pm SD; infant umbilical cord blood samples.

*NS.

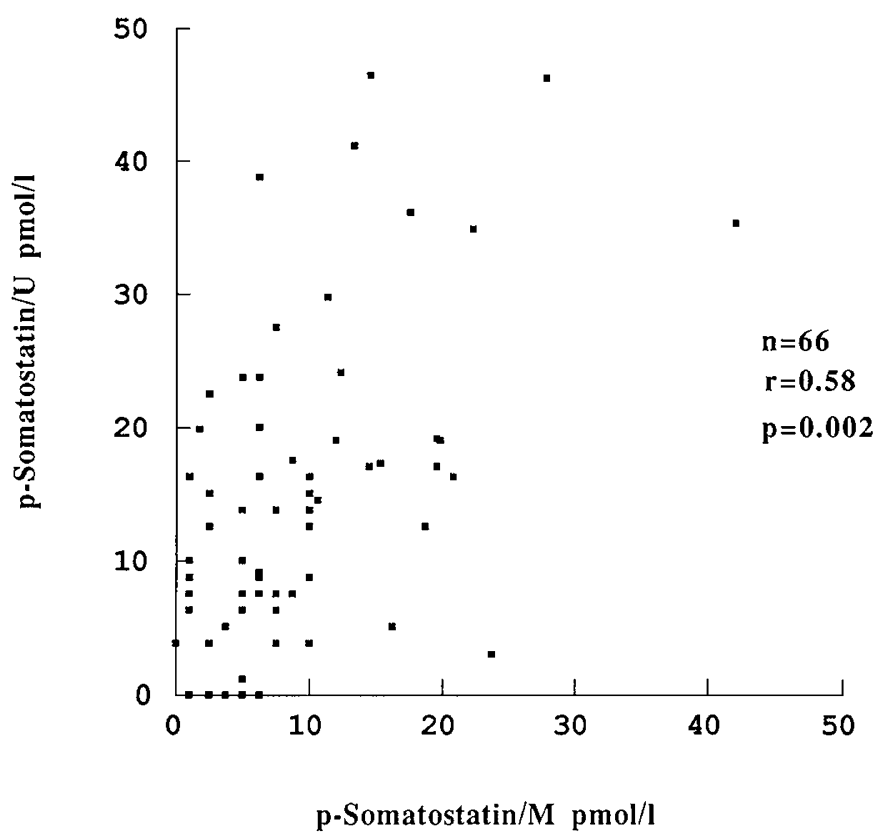

Figure 3. Plasma SS levels in mother $(M)$ after birth in relation to infant $(U)$.

Table 3. Plasma SS and plasma CCK in infants and mothers according to mode of delivery

\begin{tabular}{|c|c|c|c|c|c|}
\hline \multirow[b]{2}{*}{ Plasma } & \multicolumn{2}{|c|}{ Vaginal } & \multicolumn{2}{|c|}{$\begin{array}{l}\text { Cesarean section, } \\
\text { acute and planned }\end{array}$} & \multirow[b]{2}{*}{$p^{a}$} \\
\hline & $n$ & Level & $n$ & Level & \\
\hline \multicolumn{6}{|l|}{ Infants } \\
\hline SS & 24 & $15.3 \pm 11.8$ & 39 & $12.4 \pm 10.8$ & $*$ \\
\hline $\mathrm{CCK}$ & 18 & $12.1 \pm 5.0$ & 29 & $12.0 \pm 9.1$ & $*$ \\
\hline \multicolumn{6}{|l|}{ Mothers } \\
\hline SS & 21 & $12.1 \pm 9.3$ & 33 & $7.2 \pm 5.8$ & 0.024 \\
\hline CCK & 10 & $6.4 \pm 1.9$ & 22 & $7.4 \pm 1.7$ & $*$ \\
\hline
\end{tabular}

Values are means $\pm \mathrm{SD}$; infants umbilical cord blood samples.

${ }^{a}$ Kruskal-Wallis test.

* NS.

Figure 4 shows SS and CCK values in infants with birth weights AGA and in infants who were SGA. The mean SS and CCK levels were similar in the two groups of infants.

Table 4 compares single with multiple births. The mean SS level was significantly higher in singleton birth infants. When first born twins were compared with second born twins there

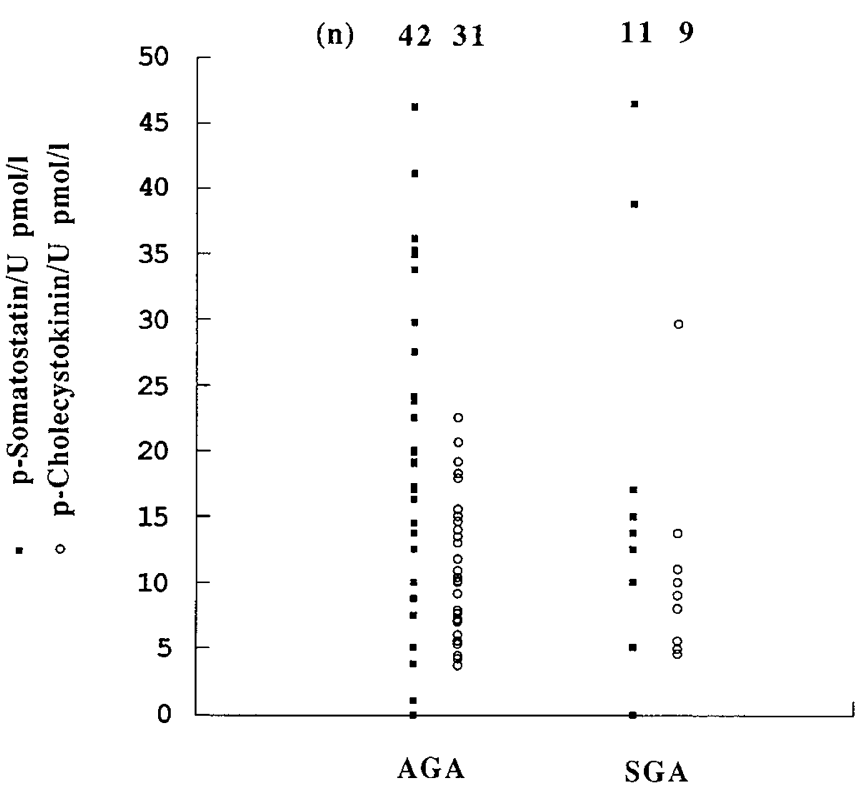

Figure 4. Plasma SS and CCK levels in infants AGA and SGA.

Table 4. Plasma SS and CCK in infants and mothers at single and multiple birth

\begin{tabular}{lcccc}
\hline & $n$ & Single & Multiple & $p$ \\
\hline Birth weight, g & $57 / 16$ & $1877 \pm 720$ & $2045 \pm 579$ & $*$ \\
Gestational age, wk & $57 / 16$ & $32.1 \pm 3.3$ & $32.7 \pm 2.7$ & $*$ \\
Umbilical pH & $49 / 13$ & $7.33 \pm 0.09$ & $7.23 \pm 0.11$ & 0.011 \\
Umbilical glucose, mmol/L $^{a}$ & $40 / 10$ & $4.0 \pm 1.5$ & $3.4 \pm 0.8$ & $*$ \\
SS, infant $^{a}$ & $55 / 16$ & $16.9 \pm 12.7$ & $9.1 \pm 7.7$ & $<0.01$ \\
CCK, infant $^{a}$ & $39 / 15$ & $11.1 \pm 5.8$ & $12.6 \pm 10.1$ & $*$ \\
SS, mother $^{a}$ & $53 / 9$ & $9.6 \pm 7.8$ & $6.9 \pm 5.1$ & $*$ \\
CCK, mother $^{a}$ & $32 / 5$ & $7.1 \pm 1.9$ & $5.9 \pm 0.8$ & $*$ \\
\hline
\end{tabular}

Values are means $\pm \mathrm{SD}$

${ }^{a}$ Values in pmol/L; infant umbilical cord blood samples.

* NS.

were no differences in the mean levels of plasma SS, plasma $\mathrm{CCK}$, blood $\mathrm{pH}$, or blood glucose between the two groups.

At the eighth gestational wk 47 of the the mothers were nonsmokers. Nine mothers smoked one to nine cigarettes a day, and three smoked more than nine cigarettes daily. At the time of birth six mothers were still smoking, most less than five cigarettes a day. There were no significant differences in the mean maternal or infant levels of plasma SS or CCK according to smoking habits in early pregnancy or at birth.

\section{DISCUSSION}

The present study of the levels of SS and CCK in preterm infants has shown that infants have higher plasma SS and CCK levels than the mothers at birth. Relatively high SS values were previously reported in term infants by Saito et al. (16) and by Marchini et al. $(17,18)$. Saito et al. (16) also observed a significant umbilical arteriovenous gradient of plasma SS levels in term infants. Altogether, these results suggest a significant endogeneous production of these peptides even in very low birth weight infants. In fact, Dubois et al. (19) and Track et al. (20) have reported the appearance of SS immunoreactive cells in antral and duodenal mucosa in fetuses of $6.5-\mathrm{cm}$ 
crown-heel length (about 10 wk of GA), and mature D-cells were found in $11-\mathrm{cm}$ fetuses. CCK-producing cells have been observed in fetal small intestinal mucosa at $10 \mathrm{wk}$ of GA (21).

The plasma SS levels in the preterm infants are of the same magnitude as those previously reported by Koshimizu et al. (22) by Saito et al. (16) (from umbilical vein) and by Marchini et al. (17) for term infants at birth. However, the plasma SS levels in the mothers delivering preterm are higher than those in mothers delivered at term (17) (7.5 versus $1 \mathrm{pmol} / \mathrm{L}$ median values). The reason for this discrepancy is not clear but may relate to the time of blood sampling in relation to the delivery in the two studies. In the present study, we obtained the samples as soon as possible after delivery, (median time 25 $\mathrm{min})$; in the previous study samples were drawn the day of operation after an overnight fasting just before the delivery.

It was suggested by Marchini et al. (18) that the high concentration of SS in cord blood is a reflection of fetal stress during labor, as they found a relationship between the SS levels and the noradrenalin levels in cord blood from term infants. Moreover, they observed a negative correlation between SS concentration and $\mathrm{pH}$ in cord arterial blood $(17,18)$. In contrast, we did not find a correlation between SS concentration and $\mathrm{pH}$ in venous cord blood from the preterm infants delivered vaginally or by cesarean section. Nor did we find a correlation between plasma SS concentration and Apgar score at $5 \mathrm{~min}$. The reason for these discrepancies between the two studies is unclear. It has been shown that the sympathoadrenal system is developed at the 20 th gestational week (23). Preterm infants have lower catecholamine levels than term infants, which is suggested to be due to immaturity of the sympathoadrenal system (24). However, the preterm infants, especially females, were found in one study (24) to manifest higher catecholamine concentrations in association with low Apgar scores $(<7)$ and acidosis $(\mathrm{pH}<7.25)$. By contrast, an earlier study (25) did not demonstrate a correlation between labor and catecholamine levels in preterm infants. It may be that the catecholamine surge at birth is not strong enough to evoke increased release of SS in the stressed and acidotic preterm infant.

To the best of our knowledge there are no reports of plasma CCK levels in preterm or term infants and mothers. Frick et al. (26) reported increasing maternal plasma CCK levels during pregnancy (from $8.7 \mathrm{pmol} / \mathrm{L}$ during the first trimester to 10.4 $\mathrm{pmol} / \mathrm{L}$ during the third trimester of pregnancy). Rådberg et al. (27) measured plasma CCK after overnight fasting in pregnant women (33-36 gestational weeks) and found plasma levels 2.2 $\pm 0.5 \mathrm{pmol} / \mathrm{L}$. These figures are comparable with our present level $(7.0 \mathrm{pmol} / \mathrm{L})$ in mothers immediately after preterm birth.

Neither plasma SS nor plasma CCK in mothers and infants showed any correlation to sex, GA, birth weight, birth length, femur length, or placental weight. There was a tendency to lower levels of plasma SS in SGA infants, but it did not reach statistical significance. It should be mentioned that all the SGA infants and $50 \%$ of the AGA infants were delivered by cesarean section. However, we could not find any significant difference in plasma SS or CCK levels in the preterm infants born vaginally versus those born by cesarean section (elective or acute). This is in contrast to an earlier report of lower plasma
SS levels in term infants delivered by elective cesarean section (17).

An interesting finding is that plasma SS levels, but not CCK levels, were significantly lower in infants born in multiple births compared with single births. It could be argued that this is because, for obvious reasons, the blood samples were taken somewhat later after delivery in multiple births than in single births. However, we could not find any correlation between plasma SS levels and time of blood sampling in our experimental setting. Moreover, the plasma SS levels were not lower in twin number two than in twin number one. Nor could we find any correlation of plasma SS levels to the mode of delivery, placental weight, Apgar score, or cord blood $\mathrm{pH}$ in the multiple or single birth groups. It could be speculated that the decreased levels of plasma SS in infants in multiple birth could be due to changes in the plasma level of other peptides such as oxytocin or estrogen. It has been shown that ingestion of estrogen-containing oral contraceptives increases the plasma levels of oxytocin and decreases the plasma levels of SS (28, 29). Inasmuch as low SS levels are known to facilitate weight gain (30), the low SS levels seen in these infants could be postulated to reflect a biologic strategy to accommodate growth by two or more fetuses.

It has been shown that smoking mothers have higher plasma SS levels than nonsmokers at $4 \mathrm{~d}$ after delivery (31). We could not confirm this finding in our smoking mothers. Their plasma SS levels immediately after birth were not different from those of nonsmoking mothers. However, the frequency of smokers in our mothers were low, only six smoked at delivery, and then fewer than five cigarettes per day.

In conclusion, the present study shows that plasma SS and $\mathrm{CCK}$ concentrations at birth are higher in preterm infants than in their mothers, indicating an endogeneous production of the peptides even in very low birth weight infants. Neither peptide level is correlated, immediately after delivery, to GA or birth weight, to Apgar score, or $\mathrm{pH}$ in venous cord blood. Finally, plasma SS is lower in infants born in multiple births than in infants born in single births.

Acknowledgement. The statistical calculations were done by Peter Anton at the Institute of Mathematical Statistics, Umeå University.

\section{REFERENCES}

1. Delvalle J, Yamada T 1990 The gut as an endocrine organ. Annu Rev Med 41:447-455

2. Marchini G, Redham I, Uvnäs-Moberg K 1992 Plasma gastrin-34 increases during and immediately after breast-feeding in 3-day-old infants. J Pediatr Gastroenterol Nutr 14:140-145

3. Uvnäs-Moberg K, Widström AM, Marchini G, Winberg J 1987 Release of GIhormones in mother and infant by sensory stimulation. Acta Paediatr Scand 76:851860

4. Aynsley-Green A, Lucas A, Lawson GR, Bloom SR 1990 Gut hormones and regulatory peptides in relation to enteral feeding, gastroenteritis and necrotizing enterocolitis in infancy. J Pediatr 117:(suppl part 2)24-32

5. Said IS 1992 Biological and physiological actions of regulatory gut peptides in the gastrointestinal tract. In: Heinz-Erian P, Deutsch J, Granditsch G (eds) Frontiers of Gastrointestinal Research. Karger, Basel, pp 49-.57

6. Walsh JH 1987 Gastrointestinal hormones. In Johnson LR (ed) Physiology of Gastrointestinal Tract. Raven Press, New York, pp 181-224

7. Hashimura E, Shimuzu F, Nishino T, Imagawa K, Haeishi K, Hamaoka T 1982 Production of rabbit antibody specific for amino terminal residues of cholecystokinin octapeptide (CCK-8) by selective suppression of cross-reactive antibody response. J Immunol Methods 55:375-387 
8. Efendic S, Nylén A, Roovete A, Uvnäs-Wallenstein K 1978 Effects of glucose and arginine on the release of immunoreactive somatostatin from the isolated perfused rat pancreas. FEBS Lett 92:33-35

9. Engström L, Karlberg P, Olsson T, Selstam U 1977 Swedish growth charts. Appendix 4. Monogr Paediatr 9:165-192

10. Lubchenco LO, Hansman C, Boyd E 1966 Intrauterine growth in length and head circumference as estimated from live birth at gestational ages from 26 to $42 \mathrm{wk}$. Pediatrics 37:403-408

11. Persson PH, Weldner BM 1986 Normal range growth curves for fetal biparietal diameter, occipito-frontal diameter, mean abdominal diameters and femur length. Acta Obstet Gynecol Scand 65:759-761

12. Bidlingmeyer BA 1984 Guidelines for proper usage of solid-phase extraction devices. LC.GC Magazine of Liquid and Gas Chromotography 2:578-580

13. Efendic S, Enzmann F, Nylén A, Uvnäs-Wallenstein K 1980 Sulfonylurea (glibenclamide) enchances somatostatin and inhibits glucagon release induced by arginine. Acta Physiol Scand 108:231-233

14. Himeno S, Tarui S, Kanayama S, Kuroshima T, Shinomura Y, Hayashi C, Tateishi K, Imagawa K, Hashimura E, Hamaoka T 1983 Plasma cholecystokinin responses after ingestion of liquid meal and intraduodenal infusion of fat, amino acids or hydrochloric acid in man: analysis with region specific radioimmunoassay. Am $\mathrm{J}$ Gastroenterol 78:703-707

15. Wilkinson, L 1989 SYSTAT: The System for Statistics. SYSTAT, Inc., Evanston, IL

16. Saito H, Saito S, Sano T, Hosoi E 1983. Fetal and maternal plasma levels of immunoreactive somatostatin at delivery: evidence for its increase in the umbilical artery and its arteriovenous gradient in the feto-placental circulation. J Clin Endocrinol Metab 56:567-571

17. Marchini G, Lagercrantz H, Winberg J, Uvnäs-Moberg K 1988 Fetal and maternal plasma levels of gastrin, somatostatin and oxytocin after vaginal delivery and elective cesarean section. Early Hum Dev 18:73-79

18. Marchini G, Lagercrantz H, Uvnäs-Moberg K 1990 Plasma gastrin and somatostatin in newborn infants and their relationship to catecholamines. J Dev Physiol 14:157162

19. Dubois PM, Paulin C, Dubois MP 1976 Gastrointestinal somatostatin cells in the human fetus. Cell Tissue Res 166:179-184
20. Track NS, Creutzfeldt C, Litzenberger J, Neuhoff C, Arnold R, Creutzenfeldt W 1979 Appearance of gastrin and somatostatin in the human fetal stomach, duodenum and pancreas. Digestion 19:292-306

21. Dubois PM, Paulin C, Chayvialle JA 1976 Identification of gastrin-secreting cells and cholecystokinin-secreting cells in the gastrointestinal tract of the human fetus and adult man. Cell Tissue Res 175:351-356

22. Koshimizu T, Ohyama Y, Yokota Y, Ohtsuka K 1985 Peripheral plasma concentrations of somatostatin-like immunoreactivity in newborns and infants. J Clin Endocrinol Metab 61:78-82

23. Lagercrantz H, Marcus C 1992 Sympathoadrenal mechanisms during development. In: Polin R, Fox W (ed) Fetal and Neonatal Physiology, WB Saunders, Philadelphia, pp $160-169$

24. Greenough A, Lagercrantz H, Pool J, Dahlin I 1992 Plasma catecholamine levels in preterm infants. Acta Paediatr Scand 76:54-59

25. Newnham JP, Marshall CL, Padbury JF, Lan R. W, Hobel CJ, Fisher DA1984 Fetal catecholamine release with preterm delivery. Am J Obstet Gynecol 149:888-893

26. Frick G, Bremme K, Sjögren C, Lindén A, Uvnäs-Moberg K 1990 Plasma levels of cholecystokinin and gastrin during the menstrual cycle and pregnancy. Acta Obstet Gynecol Scand 69:317-320

27. Rådberg G, Rehfeld JF, Cantor P, Järnfelt-Samsioe A, Samsioe G, Asztely M, Svanvik J 1987 Cholecystokinin secretion in pregnancy. Scand J Gastroenterol 22:687-690

28. Silber M, Larsson B, Uvnäs-Moberg K 1991 Oxytocin, somatostatin, insulin and gastrin concentrations vis-à-vis pregnancy, breast-feeding and oral contraceptives. Acta Obstet Gynecol Scand 70:282-289

29. Uvnäs-Moberg K, Sjögren C Westlin I Andersson PO, Stock S 1989 Plasma levels of gastrin, somatostatin, VIP, insulin and oxytocin during the menstrual cycle in women (with and without oral contraceptives). Acta Obstet Gynecol Scand 68:165-169

30. Widström AM, Matthiesen AS, Winberg J, Uvnäs-Moberg K 1989 Maternal somatostatin levels and their correlation with infant birth weight. Early Hum Dev 20:165174

31. Widström AM, Werner S, Matthiesen AS, Svensson K, Uvnäs-Moberg K 1991 Somatostatin levels in plasma in non-smoking and smoking breast-feeding women. Acta Paediatr Scand 80:13-21 